\title{
Novel Respiratory Disability Score Predicts COPD Exacerbations and Mortality in the SPIROMICS Cohort
}

This article was published in the following Dove Press journal:

International Journal of Chronic Obstructive Pulmonary Disease

\begin{abstract}
Christopher B Cooper, (D) ' Robert Paine, ${ }^{2}$ Jeffrey L Curtis, (ID ${ }^{3,4}$ Richard E Kanner, (ID) ${ }^{2}$ Carlos $\mathrm{H}$ Martinez, ${ }^{3}$ Catherine A Meldrum, ${ }^{3}$ Russell Bowler, ${ }^{5}$ Wanda O'Neal, ${ }^{6}$ Eric A Hoffman, (iD) 7 David Couper, (iD ${ }^{6}$ Miguel Quibrera, ${ }^{6}$ Gerald Criner, ${ }^{8}$ Mark T Dransfield, (ID) ${ }^{9}$ MeiLan $\mathrm{K} \mathrm{Han},{ }^{3}$ Nadia N Hansel, ${ }^{10}$ Jerry A Krishnan, (ID) "Stephen C Lazarus, ${ }^{12}$ Stephen P Peters, (DD ${ }^{13}$ R Graham Barr, ${ }^{14}$ Fernando] Martinez, (ID) ${ }^{15}$ Prescott G Woodruff ${ }^{\prime 2}$
\end{abstract}

On behalf of the SPIROMICS investigators

'Departments of Medicine and Physiology, David Geffen School of Medicine, University of California Los Angeles, Los Angeles, CA, USA; ${ }^{2}$ Section of Pulmonary and Critical Care Medicine, Department of Veterans Affairs Medical Center, University of Utah, Salt Lake City, UT, USA; ${ }^{3}$ Pulmonary and

Critical Care Medicine Division,

Department of Internal Medicine, University of Michigan Health System, Ann Arbor, MI, USA ${ }^{4}$ Veterans Affairs Ann Arbor

Healthcare System, Ann Arbor, MI, USA;

${ }^{5}$ National Jewish Health, University of

Colorado School of Medicine, Denver, CO,

USA; 'University of North Carolina Marisco

Lung Institute, Chapel Hill, NC, USA;

${ }^{7}$ Department of Radiology, University of

lowa, lowa City, IA, USA; ${ }^{8}$ Department of

Pulmonary and Critical Care Medicine,

Temple University, Philadelphia, PA, USA;

${ }^{9}$ Department of Medicine, University of

Alabama at Birmingham, Birmingham, AL,

USA; ${ }^{10}$ Johns Hopkins University School of

Medicine, Baltimore, MD, USA;

"Department of Medicine, University of

Illinois at Chicago, Chicago, IL, USA

${ }^{12}$ Division of Pulmonary and Critical Care

Medicine, Department of Medicine,

University of California San Francisco, San

Francisco, CA, USA; ${ }^{13}$ Wake Forest School

of Medicine, Winston-Salem, NC, USA;

${ }^{14}$ Department of Medicine, Columbia

University Medical Center, New York, NY,

USA; '5 Joan and Sanford I Weill Department

of Medicine, Division of Pulmonary and

Critical Care Medicine, Weill Cornell

Medicine, New York, NY, USA

Correspondence: Christopher B Cooper Departments of Medicine and Physiology,

David Geffen School of Medicine,

University of California Los

Angeles, 10833 Le Conte Avenue, 37-|31

CHS, Los Angeles, CA 90095, USA

Email ccooper@mednet.ucla.edu
Rationale: Some COPD patients develop extreme breathlessness, decreased exercise capacity and poor health status yet respiratory disability is poorly characterized as a distinct phenotype.

Objective: To define respiratory disability in COPD based on available functional measures and to determine associations with risk for exacerbations and death.

Methods: We analyzed baseline data from a multi-center observational study (SPIROMICS). This analysis includes 2332 participants (472 with severe COPD, 991 with mild/moderate COPD, 726 smokers without airflow obstruction and 143 non-smoking controls).

Measurements: We defined respiratory disability by $\geq 4$ of 7 criteria: $\mathrm{mMRC}$ dyspnea scale $\geq 3$; Veterans Specific Activity Questionnaire <5; 6-minute walking distance $<250 \mathrm{~m}$; St George's Respiratory Questionnaire activity domain $>60$; COPD Assessment Test $>20$; fatigue (FACIT-F Trial Outcome Index) $<50$; SF-12 $<20$.

Results: Using these criteria, respiratory disability was identified in 315 (13.5\%) participants (52.1\% female). Frequencies were severe COPD 34.5\%; mild-moderate COPD 11.2\%; smokers without obstruction $5.2 \%$ and never-smokers $2.1 \%$. Compared with others, participants with disability had more emphysema (13.2 vs. 6.6\%) and air-trapping (37.0 vs. $21.6 \%$ ) on HRCT $(\mathrm{P}<0.0001)$. Using principal components analysis to derive a disability score, two factors explained $71 \%$ of variance, and a cut point -1.0 reliably identified disability. This disability score independently predicted future exacerbations $(\beta=0.34$; CI $0.12,0.64$; $\mathrm{P}=0.003$ ) and death (HR 2.97; CI 1.54, 5.75; $\mathrm{P}=0.001$ ). Thus, participants with disability by this criterion had almost three times greater mortality compared to those without disability.

Conclusion: Our novel SPIROMICS respiratory disability score in COPD was associated with worse airflow obstruction as well as airway wall thickening, lung parenchymal destruction and certain inflammatory biomarkers. The disability score also proved to be an independent predictor of future exacerbations and death. These findings validate disability as an important phenotype in the spectrum of COPD.

Keywords: disability, frailty, exacerbation rate, mortality, SPIROMICS

\section{Introduction}

Activity levels and exercise capacity decline with worsening chronic obstructive pulmonary disease (COPD) and these features must therefore be thought of as important aspects of disease progression. ${ }^{1}$ Furthermore, certain patients with COPD develop respiratory disability with extreme breathlessness, decreased exercise capacity and poor health status. Maintenance of physical activity and exercise capacity is correlated with survival in COPD just as it is in patients with hypertension, diabetes and in the general population. ${ }^{2}$ Therefore, identification of respiratory disability as a phenotype of 
COPD should have important clinical consequences and could perhaps focus on specific treatment strategies.

Respiratory disability, however, is a multidimensional construct. Previous investigators have developed composite indices to address the broad components of the pathophysiology of COPD. Foremost among these is the BODE index, first described by Celli et al in $2004,{ }^{3}$ and subsequently modified. $^{4-6}$ BODE measures body mass index (BMI), airflow obstruction by percentage of reference forced expiratory volume in one second $\left(\mathrm{FEV}_{1}\right)$, dyspnea by the modified Medical Research Council scale (mMRC) and exercise performance by 6-minute walking distance (6MWD). Each of these measures has its strengths and weaknesses. mMRC is simple and easy to use but BMI is not an accurate reflection of body composition, $\mathrm{FEV}_{1}$ poorly correlates with clinical manifestations of COPD and 6MWD has serious limitations in individual patients. We sought to develop a broader multidimensional instrument that would take into account multiple symptoms, including fatigue, self-reported aerobic capacity, a prognostic indicator in cardiovascular disease, and general health status (quality of life). We were able to explore the value of adding these components using data from SPIROMICS (SubPopulations and InteRmediate Outcome Measures In COPD Study), an ongoing, multi-center, observational cohort study in COPD.

SPIROMICS was designed to identify subpopulations (phenotypes) of COPD most likely to benefit from specific therapeutic strategies. One such subpopulation, already identified, is current or former smokers with symptoms by COPD Assessment Test (CAT) score $>10$ and normal spirometry with ratio of $\mathrm{FEV}_{1}$ to forced vital capacity $\left(\mathrm{FEV}_{1} / \mathrm{FVC} \geq 70 \%\right)$. These patients with early COPD have airway wall thickening on high-resolution chest $\mathrm{CT}$ (HRCT) and respiratory exacerbations. ${ }^{7}$ Our aim in this study was to focus on the more severe end of the COPD spectrum and to develop a composite definition of disability using available measures of dyspnea, exercise capacity, fatigue and health status. The SPIROMICS study lends itself to this investigation having over 2000 richly characterized participants with varying spirometric stages of COPD as well as non-smoking controls.

\section{Methods}

\section{Study Design and Participants}

SPIROMICS recruited participants into four strata: severe COPD, mild/moderate COPD, smokers without airflow obstruction and non-smoking controls. Details of the protocol and data collection have been published elsewhere. ${ }^{8}$ Not all SPIROMICS subjects could be included in this analysis because of missing data and those who were not included are shown in Supplementary Figure S1. The study population few used consists of 2332 participants: 143 never-smokers, 726 smokers with normal spirometry $\left(\mathrm{FEV}_{1}\right.$ $/ \mathrm{FVC} \geq 70 \%$ ); formerly Global Initiative on Obstructive Lung Disease (GOLD) Stage 0, 329 with mild COPD (GOLD 1), 662 with moderate COPD (GOLD 2), 349 with severe COPD (GOLD 3) and 123 with very severe COPD (GOLD 4). We utilized clinical characteristics from baseline visits to develop a disability score and examined whether this was predictive of future exacerbations and death. This investigation was approved by the Institutional Review Boards of each SPIROMICS study site and all participants provided written informed consent. This study was conducted in accordance with the Declaration of Helsinki.

\section{Definition of Disability}

We selected seven variables from the SPIROMICS database that related to physical functioning (Supplementary Table S1). The mMRC and Veterans Specific Activity Questionnaire (VSAQ) ${ }^{9}$ were used as self-reported measures of exercise performance; 6MWD was used to represent functional exercise capacity and the activity domain of the St George's Respiratory Questionnaire (SGRQa) was used to assess the impact on health status. We also measured CAT, fatigue by the Functional Assessment of Chronic Illness Therapy Fatigue Scale (FACIT-F) and general health status by the Medical Outcomes Study Short Form-12 (SF-12). We carefully reviewed the literature to identify minimum clinically important differences and clinically meaningful cut points in each of these measures that we considered would be representative of disability. References to support these choices are included in Supplementary Table S1.

We then defined disability as having at least four of the following phenotypic characteristics: $m M R C \geq 3$, VSAQ $<5$, 6MWD $<250 \mathrm{~m}$, SGRQa $>60$, CAT $>20$, FACIT-F $<50$ and SF-12 $>20$. This approach led to a dichotomized definition of disability which was used to explore the prevalence of disability within different SPIROMICS groups such as patients with severe and very severe COPD, those with mild and moderate COPD, smokers without airflow obstruction $\left(\mathrm{FEV}_{1} / \mathrm{FVC} \geq 70 \%\right)$ and normal controls.

\section{Statistical Analysis}

We present descriptive statistics by presence or absence of respiratory disability and tested for differences between 
means of continuous variables using $t$-tests and between categorical variables using chi-squared tests. Detailed comparisons are shown in Supplementary Tables S2-S4.

As an alternative way of exploring respiratory disability, the seven variables used to identify disability were entered into a principal components analysis (PCA) seeking a linear combination of the variables that might perform better than a simple count. Using this approach, PCA simplifies the description of a set of interrelated variables. There is no dependent variable and variables are not eliminated from the model but instead summary variables, i.e. principal components are computed from all of the original variables. Typically, the first principal component explains the largest percentage of the total variance than the remaining components. The first principal component can therefore be viewed as a weighted average of most of the items. In further analyses, we used both a continuous version of the first principal component, which we have called respiratory disability score, and a dichotomized version of this score, split at the value -1.0 to separate disability from non-disability.

We explored associations between disability and other variables in the SPIROMICS baseline dataset including selfreported chronic bronchitis, history of gastroesophageal reflux (GERD) and depression identified using the Hospital Anxiety and Depression Scale (HADS). Percentage emphysema was determined on HRCT as the percentage of voxels with $\mathrm{HU}<-950^{10}$ and airway wall thickness was determined by calculating the square root of the wall area for a "theoretical airway" with an internal perimeter of $10 \mathrm{~mm}$ (Pi10). This was done for both whole lung (total Pi10) and five standardized paths (average Pi10). ${ }^{11}$ Finally, we evaluated an array of inflammatory biomarkers in patients with disability. These included WBC, CRP, fibrinogen, SERPINA1, IL-8, IL-6, sRAGE and GDF-15 (see Table 1 for an explanation of these abbreviations). We did this for each of the spirometric stages of COPD as defined by GOLD. ${ }^{12}$

To investigate associations between respiratory disability and outcomes, we used zero-inflated Poisson regression models using annual rate of exacerbations during follow-up as the outcome. The base model adjusted for age, race, sex, GOLD spirometric stage and exacerbation history in the year prior to baseline. We considered additional models adjusting for current smoking, chronic bronchitis, GERD, percentage of predicted $\mathrm{FEV}_{1}$, emphysema (as a continuous variable), anxiety and depression. We used proportional hazards regression models to investigate the association of disability with survival, adjusting for age, race, sex, exacerbation history in the year prior to baseline, chronic bronchitis, current smoking status, history of GERD, and HADS score. ${ }^{13}$ We also compared the predictive value of our respiratory disability score with the previously described composite BODE index. ${ }^{3}$

\section{Results}

Within the SPIROMICS cohort, we identified 315 (13.5\%) of all participants as having respiratory disability as defined by the presence of at least four of our seven criterion variables and, of these, approximately half $(52 \%)$ were women. The baseline data characterizing disabled versus non-disabled subjects for the whole group are presented in Table 1 . Twelve percent of men had disability compared with $15 \%$ of women $(\mathrm{P}=0.04)$. Disability was identified in 59\% of SPIROMICS subjects with very severe COPD, $26 \%$ of subjects with severe COPD, $13 \%$ of subjects with moderate COPD, $7 \%$ of subjects with mild COPD, $5 \%$ of smokers without COPD and 2\% of normal subjects. The $2 \%$ of normal subjects with disability had an average body mass index of $30 \mathrm{~kg} / \mathrm{m}^{2}$. Compared with the remaining 2017 patients in the SPIROMICS cohort, subjects with disability were slightly younger, had lower $\mathrm{FEV}_{1}$, lower $\mathrm{FEV}_{1} \%$ predicted, more emphysema on chest CT (\%lung <-950 HU at total lung capacity), more air trapping on CT (\%lung <-856 HU at residual volume), slightly greater airway wall thickness for the whole lung (total Pi10), and averaged for a set of standardized airway paths (average Pi10). Subjects with respiratory disability also had higher WBC, CRP, and fibrinogen but lower sRAGE.

Next, we compared the characteristics of disabled to nondisabled subjects in each of the SPIROMICS groups (Supplemental Tables S2-S4). The presence of four or more phenotypic characteristics of disability was associated with increasing airway wall thickness in normal subjects $(\mathrm{P}=0.021)$, smokers with normal spirometry $(\mathrm{P}=0.015)$ and patients with mild-to-moderate COPD $(\mathrm{P}<0.001)$. Disabled subjects who were never smokers or current or former smokers without airflow obstruction on spirometry were slightly younger ( 55.7 v 60.0 years; $\mathrm{P}=0.006)$, more often women (71\%), had lower $\mathrm{FEV}_{1}(2.5$ v $2.8 \mathrm{~L} ; \mathrm{P}=0.011)$, lower $\mathrm{FEV}_{1}$ $\%$ (91.8 v 97.5\%; $\mathrm{P}<0.006)$, greater average Pi10 (3.73 v $3.71 \mathrm{~mm} ; \mathrm{P}<0.036)$ and higher WBC $(7.5 \mathrm{v} 6.6 / \mathrm{mcl}$; $\mathrm{P}=0.004)$. Disabled subjects with mild or moderate COPD were also younger (60.1 v 66.2 years; $\mathrm{P}<0.001)$, more often women (58\%), had higher BMI (28.9 v $\left.27.6 \mathrm{~kg} / \mathrm{m}^{2} ; \mathrm{P}=0.050\right)$, lower $\mathrm{FEV}_{1}(1.9$ v $2.2 \mathrm{~L}$; $\mathrm{P}<0.001)$, lower $\mathrm{FEV}_{1} \%(68.2$ v 75.0\%; $\mathrm{P}<0.001)$ and greater Pi10 (3.75 v $3.72 \mathrm{~mm}$; 
Table I Clinical Characteristics of Subjects with and without Respiratory Disability*

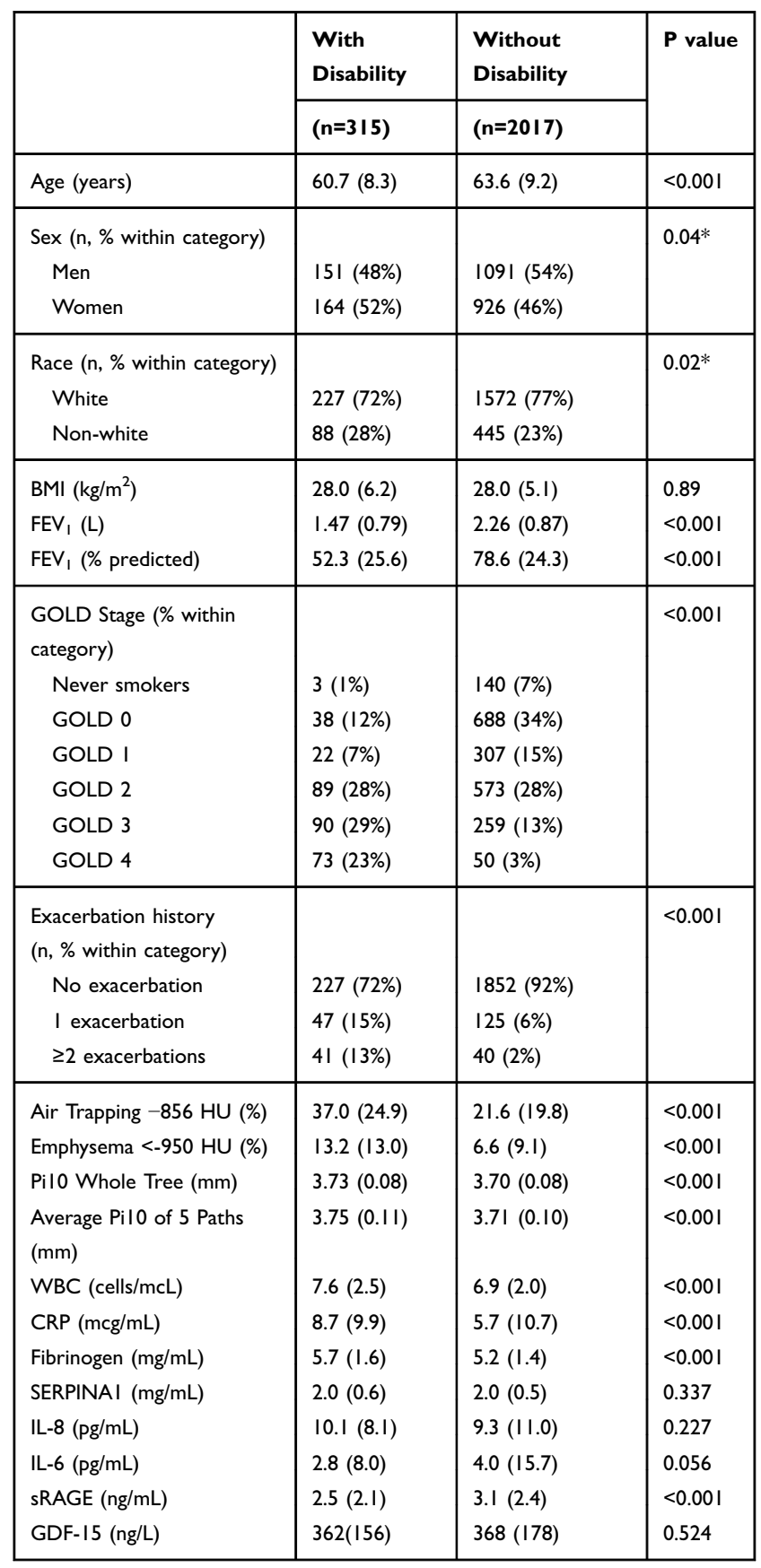

Notes: Values are Mean (SD) unless otherwise stated. Respiratory disability is defined as having $\geq 4$ disabled characteristics (see methods). *Chi-squared tests showing significant associations between disability and both sex and race.

Abbreviations: BMI, body mass index; $\mathrm{FEV}_{1}$, forced expiratory volume in one second; GOLD, Global Initiative for Obstructive Lung Disease; Pil0, square root of the wall area for a "theoretical airway" with an internal perimeter of $10 \mathrm{~mm}$; WBC, white blood cell count; CRP, C-reactive protein; SERPINAI, serpin family A, member I gene, IL-8=interleukin 8; IL-6, interleukin 6; sRAGE, soluble receptor for advanced glycation end products; GDF-15, growth differentiation factor-I5.

$\mathrm{P}<0.001)$. Disabled subjects with mild-to-moderate COPD also had higher CRP $(\mathrm{P}=0.015)$. Disabled subjects with severe or very severe COPD were again younger (62.2 v 65.8 years;
$\mathrm{P}<0.001)$, had lower $\mathrm{FEV}_{1}(0.9$ v $1.1 \mathrm{~L} ; \mathrm{P}<0.001)$, lower $\mathrm{FEV}_{1} \%$ (31.6 v 38.4\%; $\mathrm{P}<0.001$ ), more air trapping $(55.8$ $\mathrm{V} 50.0 \% ; \mathrm{P}<0.001)$ more emphysema (21.7 v 18.9\%; $\mathrm{P}=0.018$ ), but no difference in Pi10. Disabled subjects with severe and very severe COPD had higher fibrinogen (6.0 v $5.5 \mathrm{mg} / \mathrm{dL} ; \mathrm{P}=0.009$ ). Other biomarkers, including IL-6, IL-8, SERPINA1, sRAGE and GDF-15, did not discriminate between disabled and non-disabled subjects in any subgroup.

The seven variables used to define respiratory disability were entered into a principal components analysis. The first principal component which we have called "disability score" was weighted on all of the seven variables in the model and discriminated between different GOLD spirometric stages (Figure 1). The second principal component (orthogonal to the first principal component by definition) was weighted on 6-minute walking distance and fatigue but this did not discriminate between GOLD spirometric stages. Together, these first and second principal components explained $71 \%$ of the variance, whereas additional principal components each explained less than $10 \%$. Examination of the frequency distribution of our disability score in the different GOLD spirometric stages of COPD suggested a cut-point of -1.0 , where a score less than or equal to -1.0 equated to disability. Using this cut-point, $88 \%$ of patients with very severe COPD $\left(\mathrm{FEV}_{1}<30 \%\right.$ of predicted) were disabled whereas only $2 \%$ of non-smoking controls were disabled and in a separate analysis these participants were noted to have greater body weight.

Examining predictive value, we considered three definitions of respiratory disability: (a) the presence of four or more criteria of disability from the seven chosen parameters of disability in SPIROMICS; (b) disability score as a continuous variable; and (c) disability score as a dichotomous variable where a value $\leq-1.0$ equals disability. We observed that the disability score shifts to the left (more negative) with a history of more exacerbations. We then used a zero-inflated Poisson regression model to examine the probability of having (P-model) or of not having an exacerbation (P-zero). The model for predicting the rate of exacerbations which included disability score as a dichotomous variable (Table 2) performed better than models including $\geq 4$ characteristics of disability (Supplementary Table S5) or disability score as a continuous variable (Supplementary Table S6). The model which included disability score as a dichotomous variable included other significant predictors including race, sex, GOLD spirometric stage, and exacerbation history. Table 2 shows the associated P-values. Adding more variables to the Poisson regression model for the estimation of exacerbation 


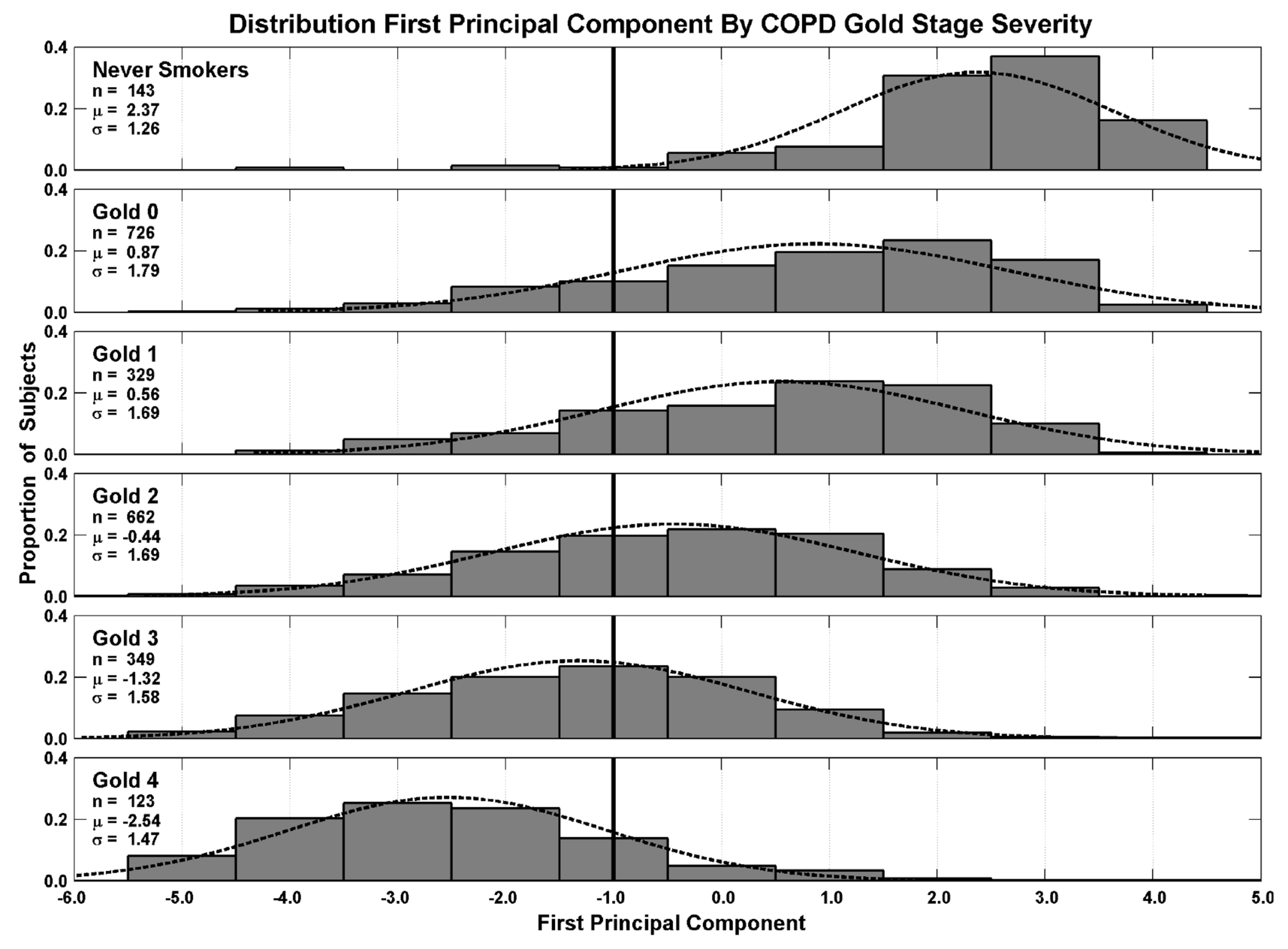

Figure I First principal component "disability score" weighted on breathlessness (mMRC), self-reported aerobic capacity (VSAQ), 6-minute walking distance, the activity domain of the St George's Respiratory Questionnaire (SGRQa), COPD Assessment Test score (CAT), fatigue (FACIT Clinical Trials) and the physical domain of the Short Form 12 (SF-12p). A value below $\leq 1.0$ was used to define disability and is shown as a bold vertical line.

rate tended to degrade the significance of the disability score. The basic model which included disability score, age, race, sex, GOLD spirometric stage and exacerbation history (6 variables) was promising but the addition of 7 more variables, such as anxiety, GERD, chronic bronchitis, current smoking, depression, emphysema (continuous variable) and percentage of predicted $\mathrm{FEV}_{1}$, did not improve the predictive quality of the model. Nevertheless, there was more disability in those with chronic bronchitis, those with emphysema and those with increasing depression by HADS score. Adding current smoking or a diagnosis of gastroesophageal reflux to the model did not reveal any relationship with disability for either of these characteristics and the presence or absence of anxiety did not seem to influence disability.

We also used a proportional hazards regression model to investigate the association of respiratory disability with survival (Table 3 and Figure 2). Only disability score $(\mathrm{P}=0.001)$, age $(\mathrm{P}=0.002)$, and history of $\geq 2$ exacerbations
$(\mathrm{P}=0.019)$ were significantly associated with mortality. Sex, race, history of chronic bronchitis, current smoking, history of GERD and depression were not statistically significant. The presence of disability (disability score $<-1.0$ ) versus no disability resulted in a 2.97-fold increase in all-cause mortality. As we might have expected, the BODE index at baseline also predicted mortality in the SPIROMICS cohort $(\mathrm{P}=0.006)$ in a model using the same covariates (Table 3 ). However, the respiratory disability score performed slightly better than BODE in terms of statistical significance.

\section{Discussion}

Severe COPD is often associated with extreme dyspnea, impaired physical functioning and deterioration of health status. ${ }^{14}$ Using the SPIROMICS cohort, we have developed a novel definition of respiratory disability that captures several aspects of each of these characteristics. Our novel 
Table 2 Estimates of Model for Exacerbation Rate Based on Presence of Respiratory Disability Using Zero-Inflated Poisson Regression

\begin{tabular}{|c|c|c|c|c|c|c|c|c|}
\hline \multirow{4}{*}{$\begin{array}{l}\text { Predictor } \\
\begin{array}{l}\text { Respiratory disability (reference disability score } \\
>-1.0)\end{array}\end{array}$} & \multicolumn{8}{|c|}{ Categorical Definition Based on Disability Score $\leq-1.0$} \\
\hline & \multicolumn{4}{|l|}{ Model } & \multicolumn{4}{|l|}{ Zero } \\
\hline & \multirow{2}{*}{$\begin{array}{l}\text { Coefficient } \\
0.379\end{array}$} & \multicolumn{2}{|c|}{$\begin{array}{l}\text { Wald 95\% } \\
\text { Confidence } \\
\text { Interval }\end{array}$} & \multirow{2}{*}{\begin{tabular}{|l} 
P-value \\
0.003
\end{tabular}} & \multirow{2}{*}{$\begin{array}{l}\text { Coefficient } \\
-0.966\end{array}$} & \multicolumn{2}{|c|}{$\begin{array}{l}\text { Wald 95\% } \\
\text { Confidence } \\
\text { Interval }\end{array}$} & \multirow{2}{*}{$\begin{array}{l}P \text {-value } \\
<0.001\end{array}$} \\
\hline & & 0.122 & 0.636 & & & -1.407 & -0.525 & \\
\hline Age (years) & -0.006 & -0.021 & 0.009 & 0.432 & -0.019 & -0.045 & 0.008 & 0.162 \\
\hline Race (reference non-white) & 0.115 & -0.129 & 0.359 & 0.353 & 1.100 & 0.590 & 1.610 & $<0.001$ \\
\hline Sex (reference female) & -0.286 & -0.522 & -0.050 & 0.018 & -0.096 & -0.494 & 0.302 & 0.635 \\
\hline GOLD stage (reference never smokers) & & & & $<0.001$ & & & & $<0.001$ \\
\hline GOLD Stage 0 & -0.516 & -1.685 & 0.653 & - & -1.406 & -3.055 & 0.242 & - \\
\hline GOLD Stage I & -0.460 & -1.627 & 0.707 & - & -2.029 & -3.706 & -0.351 & - \\
\hline GOLD Stage 2 & -0.225 & -1.360 & 0.910 & - & -2.647 & -4.276 & -1.018 & - \\
\hline GOLD Stage 3 & 0.438 & -0.675 & $\mathrm{I} .55 \mathrm{I}$ & - & -2.183 & -3.794 & -0.572 & - \\
\hline GOLD Stage 4 & 0.363 & -0.771 & 1.496 & - & -2.840 & -4.525 & -1.154 & - \\
\hline Baseline exacerbation history (reference zero) & & & & $<0.001$ & & & & 0.003 \\
\hline I exacerbation in previous year & 0.571 & 0.314 & 0.828 & - & -0.735 & -1.282 & -0.187 & - \\
\hline$\geq 2$ exacerbations in previous year & 0.631 & 0.341 & 0.922 & - & -0.902 & -1.634 & -0.170 & - \\
\hline Chronic bronchitis (reference none by self-report) & 0.085 & -0.159 & 0.329 & 0.497 & -0.527 & -0.974 & -0.079 & 0.019 \\
\hline $\begin{array}{l}\text { Current smoking (reference never/former } \\
\text { smokers) }\end{array}$ & 0.033 & -0.257 & 0.323 & 0.823 & -0.164 & -0.656 & 0.327 & 0.511 \\
\hline GERD (reference no history) & 0.055 & -0.167 & 0.276 & 0.630 & -0.249 & -0.642 & 0.145 & 0.212 \\
\hline HADS score (reference $<8$ ) & & & & 0.142 & & & & 0.788 \\
\hline HADS score 8-10 & 0.108 & -0.163 & 0.378 & - & -0.184 & -0.708 & 0.340 & - \\
\hline HADS score $>10$ & 0.331 & 0.010 & 0.652 & - & -0.056 & -0.691 & 0.579 & - \\
\hline
\end{tabular}

Notes: Model for the annual exacerbation rate (per subject, per year) using a categorical definition of respiratory disability based on SPIROMICS disability score $\leq-1.0$. Model is the regular Poisson model of an individual having an exacerbation during the period of follow-up; Zero is the model of an individual not having an exacerbation. The model shows that respiratory disability is an independent predictor of exacerbations even after correcting for GOLD spirometric stage and exacerbation history which are both themselves powerful predictors. Interestingly, being female was a predictor of having a future exacerbation whereas being non-white was a predictor of not having or perhaps not reporting a future exacerbation.

Abbreviations: GOLD, Global Initiative on Obstructive Lung Disease; Exacerbation history, exacerbations in the previous year; GERD, gastro-esophageal reflux disease; HADS, Hospital Anxiety and Depression Scale; Coefficient, $B$ in the regression model; P-value, P-value from a likelihood ratio test.

disability score proved to be an independent predictor of future exacerbations and also of mortality, even after controlling for age, sex, GOLD spirometric stage, current smoking, BMI, GERD, and depression. The development of respiratory disability is a useful concept in understanding the progression of COPD and our findings offer straightforward approaches to identifying disability in these patients.

Disability and frailty are both descriptors of physical impairment; however, disability explains how such characteristics can have negative consequences, for example, on activities of daily living. ${ }^{15}$ There have been multiple descriptions of frailty in the literature. Frailty as defined by Fried, et $\mathrm{al}^{16}$ incorporates involuntary weight loss $>10 \%$ over the preceding year, low grip strength, self-reported exhaustion, slow walking time, and low physical activity. More recently there appears to be a consensus on the definition of physical frailty which broadly includes features of diminished physiological function such as reduced strength and endurance. ${ }^{17}$ Our definition of respiratory disability has some features in common with physical frailty or limitation of physiological function.

Our novel disability score is also associated with worsening airflow obstruction as well as other factors such as lung parenchymal destruction, and depression. Interestingly, in those few patients with features of disability and GOLD spirometric Stage 0 , the disability score was associated with 
Table 3 Role of Respiratory Disability in Predicting Mortality

\begin{tabular}{|c|c|c|c|c|}
\hline \multirow[t]{2}{*}{ Variable } & \multicolumn{2}{|c|}{ SPIROMICS Disability Score } & \multicolumn{2}{|c|}{ BODE Index } \\
\hline & P-value & Hazard Ratio (95\% Cl) & P-value & Hazard Ratio (95\% Cl) \\
\hline \multicolumn{5}{|l|}{ Disability (reference disability score $>-1.0$ ) } \\
\hline Disability score $\leq-1.0$ & 0.001 & $2.97(1.54-5.75)$ & - & - \\
\hline BODE index & - & - & 0.006 & $1.20(1.05-1.36)$ \\
\hline Age & 0.002 & $1.07(1.02-1.11)$ & 0.003 & $1.06(1.02-1.11)$ \\
\hline Sex (reference female) & 0.273 & $1.39(0.77-2.49)$ & 0.346 & $1.33(0.74-2.38)$ \\
\hline Race (reference non-white) & 0.304 & $1.59(0.66-3.85)$ & 0.306 & $1.59(0.66-3.83)$ \\
\hline \multicolumn{5}{|l|}{ Baseline exacerbation history (reference none) } \\
\hline Baseline exacerbation history I & 0.303 & $1.59(0.66-3.87)$ & 0.294 & $1.62(0.66-3.97)$ \\
\hline Baseline exacerbation history $\geq 2$ & 0.019 & $3.27(1.22-8.77)$ & 0.014 & $3.53(1.29-9.36)$ \\
\hline Chronic bronchitis (reference none by self-report) & 0.870 & $0.94(0.48-1.87)$ & 0.778 & $1.10(0.56-2.18)$ \\
\hline Current smoking (reference never/former smokers) & 0.949 & $1.02(0.5 \mathrm{I}-2.07)$ & 0.856 & $1.07(0.53-2.16)$ \\
\hline GERD (reference no history) & 0.634 & $1.15(0.64-2.08)$ & 0.534 & $1.21(0.67-2.18)$ \\
\hline \multicolumn{5}{|l|}{ HADS Score (reference < 8 ) } \\
\hline HADS Score 8-10 & 0.249 & $1.59(0.72-3.50)$ & 0.098 & $1.93(0.89-4.20)$ \\
\hline HADS Score $>10$ & 0.127 & $2.10(0.8 \mathrm{I}-5.34)$ & 0.057 & $2.53(0.97-6.54)$ \\
\hline
\end{tabular}

Notes: In the model using the SPIROMICS disability score, only the disability score, age and history of $\geq 2$ exacerbations were significant independent predictors of mortality. In the model using BODE index, only BODE, age and history of $\geq 2$ exacerbations were significant independent predictors of survival.

Abbreviations: PRINI, first principal component; GERD, gastroesophageal reflux disease; HADS, hospital anxiety and depression scale.

excess body weight. Obesity certainly can account for dyspnea and activity limitation. In those with mild-moderate disease, airway wall thickening was prominent, whereas severe disease was associated with air trapping and emphysema. Another study, ${ }^{18}$ that used only 6-minute walking distance as a measure of exercise capacity, did not find any association between increased airway wall thickness and reduced functional capacity. However, 6-minute walking distance is known to be effort-dependent and highly variable within COPD patients so it is unlikely to be a useful parameter used alone in this type of analysis. Although 6-minute walking distance contributed to our disability score, our principal components analysis showed that it provided discordant (orthogonal) information as well; perhaps explaining some of the limitations of relying solely on this measure of functional exercise capacity with which to define disability.

Using the categorical definition of respiratory disability, we found interesting associations with airway disease and lung parenchymal destruction as defined by HRCT. The presence of four or more phenotypic characteristics of disability was associated with increasing airway wall thickness in normal subjects, smokers with normal spirometry and patients with mild-to-moderate COPD. In patients with severe COPD ( $\mathrm{FEV}_{1}<50 \%$ of predicted), disability was associated with greater emphysema and air trapping on HRCT. Thus, disability appears to identify unique phenotypes within spirometrically defined COPD stages.

We also explored the association of disability with a range of inflammatory biomarkers and found that some were increased in those subjects with disability compared with those without disability in the same GOLD spirometric stage. For example, disabled patients with mild-tomoderate COPD had higher WBC and CRP and disabled patients with severe COPD had higher fibrinogen. Overall, patients with disability had lower sRAGE compared to those without disability and this biomarker is recognized to decrease with progression of emphysema. These findings, although limited, suggest a role for systemic inflammation in the progression to disability. Having said this, we did not find a clear separation between those with and without disability based on a wider array of inflammatory biomarkers including IL-6, IL-8 and SERPINA1.

We explored the potential relationships between various common COPD comorbidities and respiratory disability. Secondary analyses revealed that our categorical definition of disability was associated with patient-reported diagnoses of chronic bronchitis and emphysema, and with higher depression scores. The association of disability with depression but not anxiety is interesting given that these clinical 


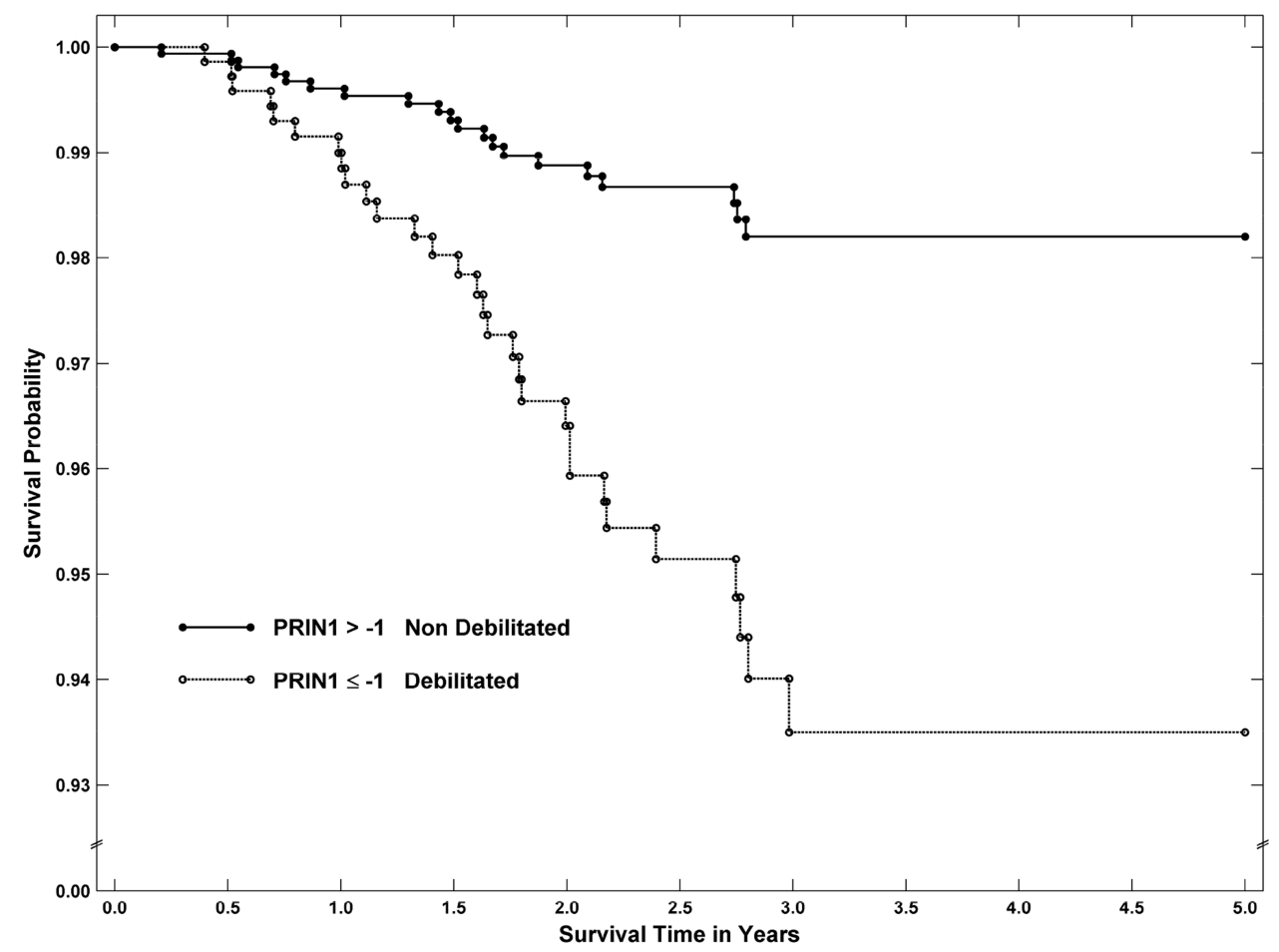

Figure 2 Kaplan-Meier estimates of the probability of survival according to whether the subjects were disabled or non-disabled as defined by having a SPIROMICS disability score $>-1.0$ or $\leq-1.0$, respectively. The hazard ratio for death in the disabled group compared with those who were not disabled was 2.56 ( $\mathrm{Cl}$ I.27, $5.3 \mathrm{I}$; $\mathrm{P}=0.009$ ).

features tend to be correlated in other studies. ${ }^{19-21}$ Furthermore, rehabilitative exercise in COPD has been shown to improve depression, ${ }^{22}$ a mechanism that might operate in part through correction of respiratory disability. In our analysis, there was no association of disability with anxiety, current smoking or GERD.

An important finding in this study was the fact that our disability score was an independent predictor of the rate of COPD exacerbations. The reduced model which included age, sex, race, GOLD spirometric stage and exacerbation history showed that the presence of disability was not only a significant predictor of exacerbation rate but also the absence of disability (PRIN1>-1.0) was a significant predictor of not having future exacerbations over the duration of this study. After adding variables to the model for current smoking, patient-reported chronic bronchitis, BMI and depression, disability remained a highly significant independent predictor not only of exacerbation rate but also of not having future exacerbations.

Equally important is our finding that the SPIROMICS disability score is an independent predictor of mortality. This is not the first time that a multidimensional index has been shown to predict survival in COPD. The BODE index ${ }^{3}$ was found to be a better predictor of survival than $F_{E V}$. Furthermore, the original BODE index which includes 6-minute walking distance was as good a predictor as a modified version of the BODE index that included directly measured oxygen uptake. ${ }^{6}$ The original BODE index was captured at the SPIROMICS baseline visit at the same time as the variables used to derive our novel disability score. Not unexpectedly, the BODE index also predicted mortality in the SPIROMICS cohort in a model adjusting for the same covariates (Table 3). Respiratory disability, however, performed slightly better than BODE in terms of statistical significance and this was perhaps because the component variables of the disability score are more broadly multidimensional. These conclusions further validate our disability score as a descriptor of end-stage or life-threatening disease. The ability to identify patients at particular risk of dying using an index of respiratory disability, such as the SPIROMICS disability score, might lead to more focused attention and treatment of this clinical phenotype with the possibility of prolonged survival.

Our study has certain limitations. Firstly, SPIROMICS was not a population-based study and may have recruited proportions of symptomatic participants that are not representative of the wider COPD population. The current SPIROMICS database includes limited physiological measurements with which to define disability and limited information on comorbidities. For example, it does not include 
specific measures of physical functioning such as 4-meter gait speed, hand-grip strength or maximum oxygen uptake. Thus, we are unable to compare the predictive value of our disability score with other measures such as a frailty score or Charlson comorbidity index. Nevertheless, we were able to include measures of breathlessness, self-reported exercise capacity, functional exercise capacity, fatigue and health status. We did our best to select those measures that relate to physical functioning and we acknowledge that some of these measures might have overlapping features. Finally, we acknowledge the complexity of some of our variables, or at least the time taken to collect the data, might limit the application of this disability score in certain clinical settings.

In summary, disease progression in COPD is classically defined by decline in pulmonary function. ${ }^{23}$ However, COPD is not fully characterized by lung function testing alone. ${ }^{24}$ Our novel SPIROMICS respiratory disability score was associated with worse airflow obstruction as well as airway wall thickening, lung parenchymal destruction and certain inflammatory biomarkers. The disability score also proved to be an independent predictor of future exacerbations and of death. These findings validate disability as an important phenotype in the spectrum of COPD. Although different from accepted definitions of frailty, respiratory disability in COPD can be thought of as equivalent to functional frailty. Future investigation is needed to validate our disability score in other cohorts, to establish its stability over time and its relationship to measures of disease progression such as the development of structural changes on HRCT or decline of $\mathrm{FEV}_{1}$. Our findings also emphasize the need to focus future research on understanding the mechanisms that lead to respiratory disability because this would predictably help identify targeted therapies that could potentially prevent progression to disability and also to prolong survival.

\section{Key Points}

\section{Question}

Certain COPD patients become disabled with extreme breathlessness, decreased exercise capacity and poor health status. Current scientific knowledge does not allow for easy identification of these individuals or provide a reliable prognosis.

\section{Results}

This study introduces a novel disability score for COPD patients based on phenotypic characteristics and shows that this score is predictive of future exacerbations and death. This score was similarly reliable at predicting death compared with another well-known composite index of COPD, the BODE index.

\section{Meaning}

Disability is an important phenotype in COPD and its recognition should lead to targeted treatment strategies to improve morbidity and survival.

\section{Acknowledgments}

\section{Participants}

The authors thank the SPIROMICS participants and participating physicians, investigators and staff for making this research possible. More information about the study and how to access SPIROMICS data is at www.spiromics.org. We would like to acknowledge the following current and former investigators of the SPIROMICS sites and reading centers: Neil E Alexis, MD; Wayne H Anderson, PhD; Mehrdad Arjomandi, MD; Igor Barjaktarevic, MD, PhD; R Graham Barr, MD, DrPH; Lori A Bateman, MSc; Surya P Bhatt, MD; Eugene R Bleecker, MD; Richard C Boucher, MD; Russell P Bowler, MD, PhD; Elizabeth E Carretta, Stephanie A Christenson, MD; Alejandro P Comellas, MD; Christopher B Cooper, MD, PhD; David J Couper, PhD; Gerard J Criner, MD; Ronald G Crystal, MD; Jeffrey L Curtis, MD; Claire M Doerschuk, MD; Mark T Dransfield, MD; Brad Drummond, MD; Christine M Freeman, PhD; Craig Galban, PhD; MeiLan K Han, MD, MS; Nadia N Hansel, MD, MPH; Annette T Hastie, PhD; Eric A Hoffman, PhD; Yvonne Huang, MD; Robert J Kaner, MD; Richard E Kanner, MD; Eric C Kleerup, MD; Jerry A Krishnan, MD, PhD; Lisa M LaVange, PhD; Stephen C Lazarus, MD; Fernando J Martinez, MD, MS; Deborah A Meyers, PhD; Wendy C Moore, MD; John D Newell Jr, MD; Robert Paine, III, MD; Laura Paulin, MD, MHS; Stephen P Peters, MD, PhD; Cheryl Pirozzi, MD; Nirupama Putcha, MD, MHS; Elizabeth C Oelsner, MD, MPH; Wanda K O’Neal, PhD; Victor E Ortega, MD, PhD; Sanjeev Raman, MBBS, MD; Stephen I. Rennard, MD; Donald P Tashkin, MD; J Michael Wells, MD; Robert A Wise, MD; and Prescott $\mathrm{G}$ Woodruff, MD, MPH. The project officers from the Lung Division of the National Heart, Lung, and Blood Institute were Lisa Postow, $\mathrm{PhD}$, and Lisa Viviano, BSN.

\section{Author Contributions}

All authors contributed to data analysis, drafting or revising the article, gave final approval of the version to be published, and agree to be accountable for all aspects of the work. 


\section{Funding}

SPIROMICS was supported by contracts from the NIH/ NHLBI (HHSN268200900013C, HHSN268200900014C, HHSN268200900015C, HHSN268200900016C, HSN26820 0900017C, HHSN268200900018C, HHSN268200900019C, HHSN268200900020C), grants from the NIH/NHLBI (U01 HL137880 and U24 HL141762), and supplemented by contributions made through the Foundation for the NIH and the COPD Foundation from AstraZeneca/MedImmune; Bayer; Bellerophon Therapeutics; Boehringer-Ingelheim Pharmaceuticals, Inc.; Chiesi Farmaceutici S.p.A.; Forest Research Institute, Inc.; GlaxoSmithKline; Grifols Therapeutics, Inc.; Ikaria, Inc.; Novartis Pharmaceuticals Corporation; Nycomed GmbH; ProterixBio; Regeneron Pharmaceuticals, Inc.; Sanofi; Sunovion; Takeda Pharmaceutical Company; and Theravance Biopharma and Mylan.

\section{Disclosure}

$\mathrm{CBC}$ has consulted with PulmonX, has received research funding from Equinox Fitness Clubs, Amgen and was employed part-time by the GlaxoSmithKline Global Respiratory Franchise, and reports personal fees from GlaxoSmithKline, outside the submitted work. RP reports grants from NHLBI, grants from COPD Foundation, NHLBI and Department of Veterans Affairs, outside the submitted work. JLC is supported by Merit Review award I01 CX000911 from the Department of Veterans Affairs, and reports grants from the Department of Defense, the National Institutes of Health, and from MedImmune Corporation, Ltd., and reports grants from NIH/NHLBI, during the conduct of the study; grants from NIH/NIAID, grants from Department of Veterans Affairs, grants from Department of Defense, personal fees from AstraZeneca, outside the submitted work. REK has no conflicts other than NHLBI contracts. CHM has NIH grants NHLBI R01HL122438-02S1 and K23 HL128936-01; personal fees, non-financial support and COPD Ad Boards, Steering Committee (honoraria, travel support) from AtraZeneca, IPF Steering Committee (publication) from Afferent/Merck, personal fees, non-financial support and COPD Advisory Board (honorarium travel) support; ILD DSMB, IPF Steering Committee, Study presentations (honoraria, travel support, publication) from Boheringer Ingelheim, teleconference without compensation from Bristol Myers Squibb, COPD Ad Board (travel support) from Chiesi, personal fees and non-financial support from
Canadian Respiratory Society, personal fees and nonfinancial support from CME Outfitters, personal fees and non-financial support from CSL Behring, personal fees from Dartmouth University, personal fees from France Foundation, personal fees from Gala, personal fees and non-financial support from Genentech, grants, personal fees, non-financial support and COPD Ad Boards, Steering Committee, DSMB (honoraria and travel support) from GlaxoSmithKline, personal fees and non-financial support from Inova Fairfax, personal fees and nonfinancial support from MDMagazine, personal fees and non-financial support from NYP Methodist Hospital Brooklyn, personal fees and non-financial support from Miller Communications, personal fees and non-financial support from National Association for Continuing Education, Steering Committee without compensation from Nitto, personal fees and non-financial support from Novartis, personal fees from New York University, personal fees and non-financial support from Patara/Respivant, personal fees from Pearl, personal fees and non-financial support from Peer View, personal fees from Physicians Education Resource, personal fees from ProMedior, personal fees and non-financial support from Rare Diseases Healthcare Communications, personal fees from Rockpointe Communications, personal fees and nonfinancial support from Sanofi/Regeneron, DSMB and Steering Committee without compensation from Biogen, personal fees and non-financial support from Sunovion, personal fees and non-financial support from Teva, teleconference without compensation from twoXR, personal fees from University of Birmingham Alabama, personal fees from UpToDate, non-financial support from Veracyte, personal fees from Vindico, personal fees and nonfinancial support from WebMD/MedScape, non-financial support and PF Ad Board (travel support) and NIH study in kind suppoRt from Zambon, non-financial support from ProTerrix Bio, personal fees from IQVIA, outside the submitted work. CM does not report any conflicts of interest. RB served on the advisory boards (GlaxoSmithKline, Boehringer Ingelheim, and Mylan Pharmaceuticals) and received research grants from GlaxoSmithKline and Boehringer Ingelheim, and reports personal fees from GlaxoSmithKline, personal fees from Boehringer Ingelheim, personal fees from Mylan Pharmaceuticals, grants from GlaxoSmithKline, grants from Boehringer Ingelheim, outside the submitted work. WO'N does not report any conflicts of interest. EAH 
a founder and shareholder of VIDA Diagnostics, a company commercializing lung image analysis software developed, and reports personal fees from VIDA Diagnostics, during the conduct of the study. DC has grants from the NIH, reports grants from NHLBI, grants from COPD Foundation, during the conduct of the study and no other conflicts. MQ reports no conflicts. GC reports grants from Boehringer-Ingelheim, Novartis, Astra Zeneca, Respironics, MedImmune, Actelion, Forest, Pearl, Ikaria, Aeris, PneumRx, Pulmonx, personal fees from HE Health Care Solutions, Inc, Amirall, BoehringerIngelheim, Holaira. MTD reports receiving grants from the $\mathrm{NIH}$, the Department of Defense, and the American Heart Association; consulting fees from Boehringer Ingelheim, GlaxoSmithKline, Novartis, Astra Zeneca, Yungjin, PneumRx/BTG, Pulmonx, Genentech, Boston Scientific, Quark Pharmaceuticals, Mereo and received grants from American Lung Association and NIH, and reports grants from NIH, during the conduct of the study; personal fees from Boehringer Ingelheim, personal fees from AstraZeneca, personal fees from GlaxoSmithKline, personal fees from Boston Scientific, grants from American Lung Association, grants from Department of Defense, grants from Department of Veterans Affairs, personal fees from Mereo, personal fees from Quark, contracted clinical trial from Gala and Nuvaira, outside the submitted work. MKH has consulted for GSK, Boehringer Ingelheim and AstraZeneca, has received research support from Novartis and Sunovion and reports grants from NIH, NHLBI, and from COPD Foundation, during the conduct of the study; and Consulting for GSK, BI, Mylan, Merck and AstraZeneca, research support from Sunovion and Novartis. NNH reports grants and personal fees from AstraZeneca, GSK, Mylan, Boehringer Ingelheim, grants from NIH, COPD Foundation, outside the submitted work. JAK has received research grants from $\mathrm{NIH}$ and the Patient Centered Outcomes Research Institute. SCL reports grants from NIH/NHLBI, during the conduct of the study. SPP reports grants from MIH, HNLBI, during the conduct of the study. The authors report no other conflicts of interest in this work. RGB has grants from the NIH, Foundation for the NIH, COPD Foundation and Alpha-1 Foundation, and reports grants, personal fees from AstraZeneca, grants from Boehringer Ingelheim, grants from NIH, grants from COPD Foundation, personal fees from Mylan, outside the submitted work. FJM reports grants from NHLBI, National Institutes of Health, personal fees from Continuing Education, personal fees from Forest Laboratories, Janssen, GlaxoSmithKline, Nycomed/Takeda, AstraZeneca, Boehringer Ingelheim, Bellerophon (formerly Ikaria), Genentech, Novartis, Pearl, Roche, Sunovion, Theravance, CME Incite, Annenberg Center for Health Sciences at Eisenhower, Integritas, InThought, National Association for Continuing Education, Paradigm Medical Communications, LLC, PeerVoice, UpToDate, Haymarket Communications, Western Society of Allergy and Immunology, Proterixbio (formerly Bioscale), Unity Biotechnology, ConCert Pharmaceuticals, Lucid, Methodist Hospital, Columbia University, Prime Healthcare Ltd, WebMD, PeerView Network, California Society of Allergy and Immunology, Chiesi, Puerto Rico Thoracic Society, outside the submitted work, and reports personal fees from Afferent/Merck, personal fees from American Thoracic Society, grants, personal fees, nonfinancial support from AstraZeneca, personal fees from Bayer, non-financial support, COPD Advisory Board (honorarium travel) support; ILD DSMB, IPF Steering Committee, Study presentations (honoraria, travel support, publication) from Boehringer Ingelehim, personal fees from ProTerrix Bio, personal fees from Bridge Biotherapeutics, personal fees, non-financial support from Chiesi, personal fees from Gala, personal fees, nonfinancial support, personal fees from Genentech, grants, personal fees, non-financial support from GlaxoSmithKline, grants, personal fees from Nitto, personal fees from ProMedior, personal fees from ProMetic, personal fees from Patara/Respivant, personal fees from Biogen, personal fees from Physicians Education Resource, personal fees from ProMedior, personal fees, non-financial support from Sunovion, personal fees, nonfinancial support from Teva, personal fees from Veracyte, teleconference without compensation from Bristol Myers Squibb, twoXR, personal fees and non-financial support from Canadian Respiratory Society, CME Outfitters, Inova Fairfax, MDMagazine, NYP Methodist Hospital Brooklyn, Miller Communications, Rare Diseases Healthcare Communications, Sanofi/Regeneron, CSL Behring, Novartis, WebMD/MedScape, personal fees from France Foundation, New York University, Rockpointe Communications, University of Birmingham Alabama, Vindico, Dartmouth University, DSMB and Steering Committee without compensation from Biogen, and IPF Ad Board (travel support) and NIH study in kind support 
from Zambon, during the conduct of the study. PGW reports personal fees from Glenmark Pharmaceuticals, personal fees from GSK, personal fees from NGM Pharma, personal fees from Amgen, Regeneron, 23andMe, Theravance, AstraZeneca, Sanofi, Glenmark Pharmaceuticals, Theravance, NGM Pharma, Amgen, and Genentech, outside the submitted work. The authors report no other conflicts of interest in this work.

\section{References}

1. Cooper CB. Airflow obstruction and exercise. Respir Med. 2009;103 (3):325-334. doi:10.1016/j.rmed.2008.10.026

2. Myers J, Prakash M, Froelicher V, Do D, Partington S, Atwood JE. Exercise capacity and mortality among men referred for exercise testing. $N$ Engl J Med. 2002;346(11):793-801. doi:10.1056/ NEJMoa011858

3. Celli BR, Cote CG, Marin JM, et al. The body-mass index, airflow obstruction, dyspnea, and exercise capacity index in chronic obstructive pulmonary disease. $N$ Engl J Med. 2004;350(10):1005-1012. doi:10.1056/NEJMoa021322

4. Roberts MH, Mapel DW, Bruse S, Petersen H, Nyunoya T. Development of a modified BODE index as a mortality risk measure among older adults with and without chronic obstructive pulmonary disease. Am J Epidemiol. 2013;178(7):1150-1160. doi:10.1093/aje/kwt087

5. Moberg M, Vestbo J, Martinez G, et al. Validation of the i-BODE index as a predictor of hospitalization and mortality in patients with COPD participating in pulmonary rehabilitation. COPD. 2014;11 (4):381-387. doi:10.3109/15412555.2013.836171

6. Cote CG, Pinto-Plata VM, Marin JM, Nekach H, Dordelly LJ, Celli BR. The modified BODE index: validation with mortality in COPD. Eur Respir J. 2008;32(5):1269-1274. doi:10.1183/ 09031936.00138507

7. Woodruff PG, Barr RG, Bleecker E, et al. Clinical significance of symptoms in smokers with preserved pulmonary function. $N$ Engl J Med. 2016;374(19):1811-1821. doi:10.1056/NEJMoa1505971

8. Couper D, LaVange LM, Han M, et al. Design of the subpopulations and intermediate outcomes in COPD study (SPIROMICS). Thorax. 2014;69:491-494. doi:10.1136/thoraxjnl-2013-203897

9. Myers J, Bader D, Madhavan R, Froelicher V. Validation of a specific activity questionnaire to estimate exercise tolerance in patients referred for exercise testing. Am Heart J. 2001;142(6):1041-1046. doi:10.1067/mhj.2001.118740

10. Gevenois PA, De Vuyst P, de Maertelaer V, et al. Comparison of computed density and microscopic morphometry in pulmonary emphysema. Am J Respir Crit Care Med. 1996;154:187-192. doi:10.1164/ajrccm.154.1.8680679
11. Grydeland TB, Dirksen A, Coxson HO, et al. Quantitative computed tomography: emphysema and airway wall thickness by sex, age and smoking. Eur Respir J. 2009;34(4):858-865. doi:10.1183/ 09031936.00167908

12. Vestbo J, Hurd SS, Agusti AG, et al. Global strategy for the diagnosis, management, and prevention of chronic obstructive pulmonary disease: GOLD executive summary. Am J Respir Crit Care Med. 2013;187(4):347-365. doi:10.1164/rccm.201204-0596PP

13. Zigmond AS, Snaith RP. The hospital anxiety and depression scale. Acta Psychiatr Scand. 1983;67(6):361-370. doi:10.1111/j.16000447.1983.tb09716.x

14. Cooper CB. The connection between chronic obstructive pulmonary disease symptoms and hyperinflation and its impact on exercise and function. $A m \quad J \quad$ Med. 2006;119(10):21-31. doi:10.1016/j. amjmed.2006.08.004

15. Morley JE, Haren MT, Rolland Y, Kim MJ. Frailty. Med Clin North Am. 2006;90(5):837-847. doi:10.1016/j.mena.2006.05.019

16. Fried LP, Tangen CM, Walston J, et al. Frailty in older adults: evidence for a phenotype. J Gerontol a Biol Sci Med Sci. 2001;56 (3):M146-M156. doi:10.1093/gerona/56.3.M146

17. Abellan van Kan G, Rolland YM, Morley JE, Vellas B. Frailty: toward a clinical definition. J Am Med Dir Assoc. 2008;9(2):71-72. doi:10.1016/j.jamda.2007.11.005

18. Kirby M, Pike D, Sin DD, Coxson HO, McCormack DG, Parraga G. COPD: do Imaging Measurements of emphysema and airway disease explain symptoms and exercise capacity? Radiology. 2015;277 (3):872-880. doi:10.1148/radiol.2015150037

19. Bernard P, Ninot G, Moullec G, Guillaume S, Courtet P, Quantin X. Smoking cessation, depression, and exercise: empirical evidence, clinical needs, and mechanisms. Nicotine Tob Res. 2013;15 (10):1635-1650. doi:10.1093/ntr/ntt042

20. De Miguel Díez J, Hernandez BV, Puente ML, Carrasco GP, Gomez GT, Jimenez GR. Prevalence of anxiety and depression among chronic bronchitis patients and the associated factors. Respirology. 2011;16 (7):1103-1110. doi:10.1111/j.1440-1843.2011.02015.x

21. Quint JK, Baghai-Ravary R, Donaldson GC, Wedzicha JA. Relationship between depression and exacerbations in COPD. Eur Respir J. 2008;32(1):53-60. doi:10.1183/09031936.00120107

22. Paz-Diaz H, Montes de Oca M, Lopez JM, Celli BR. Pulmonary rehabilitation improves depression, anxiety, dyspnea and health status in patients with COPD. Am J Phys Med Rehabil. 2007;86:30-36. doi:10.1097/PHM.0b013e31802b8eca

23. Fletcher $\mathrm{C}$, Peto R. The natural history of chronic airflow obstruction. Br Med J. 1977;1:1645-1648. doi:10.1136/bmj.1.6077.1645

24. Han MK, Agusti A, Calverley PM, et al. Chronic obstructive pulmonary disease phenotypes: the future of COPD. Am J Respir Crit Care Med. 2010;182:598-604. doi:10.1164/rccm.200912-1843CC

\section{Publish your work in this journal}

The International Journal of COPD is an international, peer-reviewed journal of therapeutics and pharmacology focusing on concise rapid reporting of clinical studies and reviews in COPD. Special focus is given to the pathophysiological processes underlying the disease, intervention programs, patient focused education, and self management protocols. This journal is indexed on PubMed Central, MedLine and CAS. The manuscript management system is completely online and includes a very quick and fair peer-review system, which is all easy to use. Visit http://www.dovepress.com/testimonials.php to read real quotes from published authors. 